\title{
La Capacocha como ritual político. Negociaciones en torno al poder entre Cuzco y los curacas
}

La Capacocha comme rituel politique. Les négociations au sujet du pouvoir entre Cuzco et les curacas

The Capacocha as political ritual. Negotiations of power between Cuzco and the curacas

\section{Annette Schroedl}

\section{OpenEdition} Journals

\section{Edición electrónica}

URL: http://journals.openedition.org/bifea/3218

DOI: 10.4000/bifea.3218

ISSN: 2076-5827

Editor

Institut Français d'Études Andines

\section{Edición impresa}

Fecha de publicación: 1 abril 2008

Paginación: 19-27

ISSN: 0303-7495

Referencia electrónica

Annette Schroedl, « La Capacocha como ritual político. Negociaciones en torno al poder entre Cuzco y los curacas », Bulletin de l'Institut français d'études andines [En línea], 37 (1) | 2008, Publicado el 01 octubre 2008, consultado el 27 noviembre 2020. URL : http://journals.openedition.org/bifea/3218 ; DOI : https://doi.org/10.4000/bifea.3218

\section{c) $(7) \bigcirc$}

Les contenus du Bulletin de l'Institut français d'études andines sont mis à disposition selon les termes de la licence Creative Commons Attribution - Pas d'Utilisation Commerciale - Pas de Modification 4.0 International. 


\title{
La Capacocha como ritual político. Negociaciones en torno al poder entre Cuzco y los curacas*
}

\author{
Annette Schroed ${ }^{* *}$
}

\begin{abstract}
Resumen
Este artículo estudia las funciones que los rituales políticos tenían en el estado inca a través del análisis de la fiesta de la Capacocha. Las ceremonias públicas de la religión estatal proporcionaban el escenario en el cual se negociaron las relaciones políticas entre el soberano y sus súbditos, entre Estado y pueblos conquistados por los incas e incorporados en su imperio. De este modo, los rituales políticos contribuyeron a la consolidación del dominio de los incas sobre los pueblos andinos. Los rituales incaicos otorgaron especial atención al establecimiento de relaciones con las élites regionales, es decir con los curacas de los pueblos recientemente sojuzgados, y a la reafirmación de lazos que unían los pueblos andinos con Cuzco, la capital incaica. El artículo enfocará sobre todo esta relación entre poder estatal y autoridades locales en el imperio de los incas.
\end{abstract}

Palabras claves: Inca, curacas, ritual, Capacocha, consolidación del dominio, relaciones políticas

\section{La Capacocha comme rituel politique. Les négociations au sujet du pouvoir entre Cuzco et les curacas}

\section{Résumé}

Cet article étudie la fonction des rituels politiques dans l'état inca à travers l'analyse du cycle rituel de la Capacocha. Les cérémonies publiques de la religion d'État servaient de toile de fond aux négociations qui établissaient les relations politiques entre le souverain et ses subordonnés, c'est-à-dire les relations

* Departamento de Antropología Histórica, Universidad Goethe, Francfort del Meno, Alemania. E-mail: annette. schroedl@arcor.de

** Quisiera dar particularmente las gracias a mi asesora, la Doctora Iris Gareis, por haberme ofrecido la oportunidad de participar como ponente en el $52^{\circ}$ Congreso de Americanistas en Sevilla (julio 2006). 
entre l'État et les peuples conquis et incorporés à l'empire inca. De cette manière, les rituels politiques contribuaient à la consolidation du pouvoir exercé par Cuzco sur les peuples andins. De plus, les rituels inca servaient à nouer des relations avec les élites locales, principalement les curacas, et à resserer les liens qui unissaient les peuples andins à l'état inca. L'article sera particulièrement consacré à cette relation entre le pouvoir étatique et les autorités locales au sein de l'empire inca.

Mots clés : Inca, curacas, Capacocha, rituel, consolidation du pouvoir, relations politiques

\title{
The Capacocha as political ritual. Negotiations of power between Cuzco and the curacas
}

\begin{abstract}
The aim of this article is to study the function of political rituals in the Inca state through the analysis of the Capacocha ritual cycle. The public ceremonies of the Inca state religion created a scene where political relations between the sovereign and his subordinates (i.e. the relations between the Inca state and the peoples that had been conquered and incorporated into the Inca realm) were being negotiated, thus contributing to the consolidation of power that Cuzco exercised upon the Andean peoples. Furthermore, the Inca rituals paid special attention to the establishment of relations with the local elites, mainly with the curacas, and to the reaffirmation of the ties that united the Andean peoples with the Inca state. The article will focus on this relation between state power and local authorities in the Inca realm.
\end{abstract}

Key words: Inca, curacas, Capacocha, ritual, consolidation of power, political relations

La cuestión de la incorporación de los diversos grupos locales andinos al imperio de los incas no se acaba con el tratamiento escrupuloso de los éxitos y límites de la conquista militar incaica. Tampoco con la referencia al ingenioso sistema infraestructural y administrativo con el cual los incas lograron no solo enlazar los lugares más alejados del imperio con la capital del Cuzco a través de caminos, puentes y centros administrativos sino también controlar a los grupos recién sometidos por medio de un amplio sistema de cargos de funcionarios del Estado. Para poder tratar la cuestión planteada de una manera más exhaustiva sería útil incluir también otro aspecto más abstracto: la ideología del dominio incaico. En mi opinión, ésta desempeñaba un papel importante para que los incas pudieran lograr vincular el poder de las autoridades locales, es decir de los curacas, a largo plazo con su dominio centralizado en Cuzco. En este contexto, los rituales colectivos representaban un medio particularmente apto para trasladar la ideología de dominación a los súbditos.

En el presente artículo expondré primero una parte teórica, ofreceré un planteamiento para poder determinar cuál es la diferencia entre los rituales en general y los rituales políticos; luego daré un ejemplo de un ritual incaico y mostraré los motivos por los cuales puede ser considerado como ritual político.

\section{EL RITUAL Y LA POLÍTICA: DOS ÁMBITOS ENTRETEJIDOS}

Primero, para dar una definición de rituales en general quisiera referirme a la antropóloga Åsa Boholm quien los determina de la manera siguiente: 
«El ritual sirve para articular significados simbólicos por medio de los actos expresivos que tienen lugar en un escenario litúrgico arreglado de manera formalizada y estandarizada» (Boholm, 1996: 2) (la traducción es mía).

Eso quiere decir que los rituales transmiten mensajes al público mediante la actuación en un ambiente formal y bien reglamentado. También se desprende de esta misma cita lo que es la función principal de los rituales, a saber la comunicación (véase también Gareis, 2005: 3). Pero este tipo de comunicación excede la pura comunicación verbal en el sentido de que los rituales comunican asuntos que no se suelen discutir explícitamente en la vida cotidiana de una sociedad. Es decir que en los rituales mucho se está desarrollando en el ámbito de los símbolos culturales. Bien es verdad que éstos son esenciales para una sociedad para darle orden y estructura. Pero no están pensados conscientemente ya que los miembros de la misma cultura los dan por hecho (Boholm, 1996: 2-3). En resumidas cuentas, los rituales comprenden mensajes en clave que se suelen expresar a través de la actuación.

¿Cómo definir entonces los rituales políticos? Primero hay que retener que no existe una separación estricta entre los rituales en general y los rituales políticos en particular. Más bien se puede decir que los rituales políticos se encuentran justamente entre el ámbito de la política y el de la religión. La mayoría de los rituales reflejan de cierta manera las estructuras del poder de una sociedad y por eso tienen de por sí un componente político (Boholm, 1996: 5-6). A través del efecto sinérgico que suele hacerse sentir en los rituales colectivos estas estructuras del poder se interiorizan por parte de los participantes, como lo describe Åsa Boholm:

«La participación en el ritual probablemente promueve una motivación poderosa en los individuos para subordinarse a la autoridad»(Boholm, 1996: 1) (la traducción es mía).

Así como se puede afirmar que cada ritual tiene una dimensión política se puede sostener, por otra parte, que ciertos rituales forman una parte indispensable de la política. Eso se ve muy bien, por ejemplo, en rituales que acompañan una toma de mando o una entronización porque son justamente estos los que están transformando a un individuo en una personalidad de la vida pública con autoridad política: estos rituales transmiten la integridad necesaria del candidato y la legalidad del acto, lo que significaría, por siguiente, en el caso de la entronización de un soberano, la legitimidad de su derecho al poder (Boholm, 1996: 3-4). Por otro lado, la dimensión religiosa de los rituales políticos se distingue por supuesto más claramente en sociedades en las que el dominio necesita ser justificado religiosamente - como era el caso en el imperio de los incas dónde el Inca se legitimaba como hijo del sol (Gareis, 2005: 4-5) -.

Así como todos los rituales, los rituales políticos también se celebran o con regularidad o quedan reservados para ciertas ocasiones. En este caso muchas veces se trata de rituales transitorios — según la teoría de van Gennep (véase Turner, 1969)—, ya que tienen lugar en cualquier crisis social para poder superar el estado transitorio amenazante.

Los actores de los rituales políticos colectivos constan por una parte de la sociedad o cualquier grupo social, y por otra del Estado o de una autoridad política. Después de todo, el negociar la relación entre estos dos partidos es justamente lo que se puede considerar como función principal de los rituales políticos (Gareis, 2005: 3, 5).

\section{LA CAPACOCHA: DISCUTIDA EN VARIOS SENTIDOS}

Para exponer de forma más concreta el papel que desempeñaban los rituales políticos en el incario, escogí un ejemplo que — como veremos— estaba negociando de modo muy 
específico la relación entre Cuzco y las provincias del imperio de los incas, entre el dominio incaico y las autoridades locales respectivamente. Me refiero a la llamada Capacocha: la Capacocha era uno de los rituales más importantes de los incas en el que participaron los súbditos de las cuatro partes del imperio para dar ofrendas a las huacas del imperio. También ocurrió que en esta ocasión se sacrificaron seres humanos.

Para comenzar es digno de mención que en las fuentes que están a nuestra disposición en relación con este ritual — como crónicas, visitas o documentos jurídicos- el término de Capacocha se usa de diversas maneras. A veces la Capacocha es equiparada con los sacrificios humanos; otras veces se habla de la Capacocha sin que el texto determinado evoque los sacrificios humanos; a veces las ofrendas en general se denominan como Capacocha; otras veces designa el ritual entero. El significado exacto del término Capacocha está aclarado aún menos definitivamente: varios etnohistoriadores intentaron dar una interpretación adecuada partiendo de la expresión en lengua quechua (Qhapaq hucha) reconstruida a partir de la palabra hispanizada Capacocha, pero han llegado a conclusiones diferentes. María Rostworowski (1970) y Tom Zuidema (1973), por ejemplo, tradujeron hucha como «pecado» e interpretaron Qhapaq hucha, por consiguiente, como «pecado del soberano» 1 mientras que Henrique Urbano opinaba que la palabra hucha implicaría más bien una función suplente, o sea una «ofrenda vicarial», en el sentido de que el Inca realizaba los sacrificios humanos representándose a sí mismo. Según esta idea —como lo sostiene Urbano- el Inca solía estar presente personalmente en el puro gesto sacrificial (véase Urbano in Molina, 1988 [1575]: 120-121). Es obvio entonces que la aclaración del significado exacto de la Capacocha sigue siendo un problema no resuelto totalmente.

Pero aparte de la cuestión de denominación, existen muy pocas fuentes que descartan explícitamente que hubo sacrificios humanos en el incario, como por ejemplo los Comentarios reales del Inca Garcilaso de la Vega quien lo niega. Sin embargo queda muy claro que con su afán de presentar a los incas como civilizadores de los pueblos andinos, en su obra tal confesión hubiera surtido un efecto contraproducente. Más bien, el Inca Garcilaso está proyectando la existencia de los sacrificios humanos hacia las provincias lejanas de la capital incaica donde siguen efectuándose como vestigios de un pasado preincaico 2 . Por lo tanto, el atribuir la costumbre de los sacrificios humanos a los incas se debe — según la argumentación suya — a estudios insuficientes por parte de sus colegas:

«Si algunos historiadores lo han escrito fue porque los relatores los engañaron, por no dividir las edades y las provincias, dónde y cuándo se hacían los semejantes sacrificios de hombres, mujeres y niños» (Garcilaso de la Vega, 1991 [1609]: 88)³.

Otros cronistas sabían relativizar este tema delicado tratándolo más en detalle —como lo hacían por ejemplo Martín de Murúa (1986 [1611]: 420), Cristóbal de Molina de Cuzco

1 Véase Zuidema (1982: 425-427) respecto al concepto del pecado en el incario.

2 De hecho queda comprobado que los sacrificios humanos se solían efectuar en los Andes ya desde hace mucho tiempo antes del incario. Sin embargo, eso no significa necesariamente que los incas se negaron a institucionalizar esta costumbre en su propio Estado cuzqueño: como indica Margarita Gentile, basándose en la obra de Levillier los incas la tomaron de los collas en vista de su fuerza bélica extraordinaria —una conección que Gentile (1996: 51) considera «muy probablemente porque la capacocha, al extender la red de reciprocidades aumentaba la capacidad operativa para la guerra»-

3 A través de varias investigaciones arqueológicas el punto de vista del Inca Garcilaso de la Vega había sido rebatido, independientemente de las fuentes escritas. La aclaración de esta cuestión se debe particularmente a los trabajos de Johan Reinhard quien se dedicó a partir de 1980 a la investigación de plataformas ceremoniales y santuarios de los incas en alta montaña (véase por ejemplo Reinhard, 1992; 2002). El hallazgo espectacular de una niña momificada en el volcán de Ampato (Perú) en 1995, y de otros cuerpos ofrendados mostró claramente que sí había sacrificios humanos en el imperio de los incas (Chávez, 2001; Hagen \& Morris, 1998: 218-219). Para una detallada contextualización histórica y sociocultural de una Capacocha, en base al hallazgo de un niño ofrecido en el cerro Aconcagua (Argentina), véase el artículo de Margarita Gentile (1996). 
(1988 [1575]: 127) y Pedro Cieza de León (1985 [155?])—. Éste subraya, por ejemplo, que solamente a las huacas más importantes del imperio se les solían hacer sacrificios humanos, puesto que existía una jerarquia bien elaborada de las ofrendas que habían de corresponder a la importancia de las respectivas huacas. Cieza también nos da a conocer lo que le motivó a dedicarse a este tema:

«Esto digo, porque la opinión que los españoles tenemos en afirmar que en todos los templos sacrificaban hombres es falsa; y esto es la verdad, según lo que yo alcancé» (Cieza de León, 1985 [155?]: 103).

El análisis básico de este ritual se debe a Pierre Duviols (1976) quien describió la Capacocha usando la metáfora convincente del sistema circulatorio del cuerpo humano —en el sentido de que la Capacocha como sistema circulatorio aseguraba el intercambio existencial entre las provincias y la capital de Cuzco, así como lo desempeña el sistema circulatorio del cuerpo humano entre los miembros y el corazón-. Cristóbal de Molina de Cuzco (1988 [1575]: 120-128) nos da una descripción muy detallada del ritual: al celebrar la Capacocha se ponían en camino delegaciones desde todas las provincias del imperio con ofrendas (tales como coca, oro, plata, cumbi/tejido fino, llamas etc. y también niños escogidos) y con objetos de culto de sus huacas más importantes. Una vez llegados a la plaza central de Cuzco, los escogidos para los sacrificios tenían que rodear los ídolos incaicos en presencia del Inca — un acto mediante el cual todas las ofrendas adquirían un aura sagrada (Bravo Guerreira, 1985: 290)_. Luego el Inca mandaba repartir las ofrendas entre los sacerdotes con orden de sacrificarlas in situ a las huacas locales. No obstante, los primeros sacrificios ya se habían realizado en Cuzco mismo, dedicados a los principales ídolos incaicos, a saber al Creador, al Sol, al Trueno y a la Luna. Después de los actos solemnes en Cuzco, las delegaciones regresaban a sus provincias llevando sus objetos de culto y las ofrendas. De este modo difundían la Capacocha por todo el imperio.

\section{LA DIMENSIÓN POLÍTICA DE LA CAPACOCHA}

¿En qué consistía entonces la dimensión política de la Capacocha? Como nos ha llegado por Cristóbal de Molina de Cuzco que apuntó algunas de las oraciones públicas de los sacerdotes en Cuzco, ellos oraron por el bienestar del Inca y sus súbditos, es decir, por el éxito militar, la salud y una larga vida para el Inca, por la prosperidad, la salud y la paz entre los súbditos:

«Rogándole [al Hacedor] tuviese por bien de dar larga vida y salud y vitoria contra sus enimigos al Ynga no llevándole en su mocedad, y a sus hijos y descendientes; que mientras este Ynga fuese señor, todas las naciones que sujetas tuviese, siempre estuviesen en paz y multiplicasen, y tuviesen comidas, y que siempre fuesen vencedor» (Molina de Cuzco, 1988 [1575]: 123).

Como se ve, se trata del mantenimiento de la sociedad y del equilibrio político. El bienestar del Inca como representación o personificación del Estado era, por consiguiente, de suma importancia y el garante para el equilibrio político (Gareis, 1987: 64; 2003: 2). Así parece lógico que hubiera dos formas de Capacocha: según Martín de Murúa (1986 [1611]: 420), por ejemplo, los sacrificios humanos se practicaban en el imperio de los incas solo en tiempos de crisis —al contrario de lo que se hacía en el México antiguo-:

«No se hacían con la frecuentación que se refiere haberse usado en México y sus provincias, donde era en gran multitud. Acá era para negocios de muchísima importancia, como en tiempo de grandísima hambre o pestilencia o mortandad». 
Según Cristóbal de Molina de Cuzco (1988 [1575]: 122) la Capacocha también se celebraba con motivo de la entronización del Inca. Ambos casos pueden ser considerados como típicos rituales transitorios en el sentido de la teoría de van Gennep, ya que se efectuaron en una crisis social o fase transitoria para superar el estado de excepción. En el manuscrito de Huarochirí (Salomon \& Urioste, 1991 [21608?]: 112), por otra parte, se encuentra un indicio que la Capacocha tenía lugar regularmente, a saber cada año. Presumiblemente coexistían ambas formas de celebrar la Capacocha, por una parte con el propósito de combatir una fase de inestabilidad y por la otra para reafirmar siempre el orden social.

Dado que todas las provincias participaron en el ritual de la Capacocha por parte de sus delegaciones o sitios de culto, evidentemente se fortalecieron las relaciones entre el Cuzco y las provincias, y entre el Inca y los curacas respectivamente (Hagen \& Morris, 1998: 218). Al mismo tiempo el caminar al Cuzco representaba — metafóricamente dicho- un acto de sumisión a la autoridad del Inca. Es decir que a través de la participación en la Capacocha se asignaron a los grupos locales y sus representantes sus roles dentro del estado inca (Gareis, 2003: 19), a saber, sus roles como súbditos o autoridades bajo la dirección del soberano inca. Mediante la actuación, estas estructuras del poder se afirmaron a la vez que los participantes se concienciaron de ellas y las interiorizaron.

Para el Inca los sacrificios a todas las huacas del imperio eran de suma importancia para no enfurecer a ninguna de ellas. Pero la intención más profunda de esto era controlar los cultos locales y en parte instrumentalizarlos para el Estado incaico. Eso se puede ver muy bien con ocasión de la interrogación de las huacas como oráculo que también ocurría durante la Capacocha (Cieza de León, 1985 [155?]: 104): mediante los sacerdotes todas las huacas de las provincias debían dar profecías sobre el futuro cercano del incario (si iba a surgir alguna rebelión, una guerra o si por ej. el Inca iba a gozar de buena salud) y si alguna profecía terminaba siendo verdad, la huaca respectiva era recompensada por el Inca. Eso quiere decir que en la Capacocha se trataba también de una apropiación de cultos y santuarios locales con la que la autoridad sagrada local fue subordinada a la autoridad del Inca.

Además, los escogidos para los sacrificios no solo debían ser niños de unos diez años absolutamente íntegros y sanos, sino que también debían provenir de las provincias (Rowe, 1946: 306). En un ritual como el de la Capacocha que está tratando las relaciones entre Cuzco y las provincias eso no es extraño. Incluso el Inca se ocupó de que los niños y niñas sacrificados fuesen venerados como huacas en su tierra natal y que fuesen proveídos con sus propios sacerdotes para el mantenimiento de su culto (Hernández Príncipe, 1986 [1622]: 472-473). Con eso el estado incaico propició la posibilidad de influir en la creación de nuevas huacas y de sus cultos en las provincias, y de hacerles controlables al mismo tiempo. Hernández Príncipe quien viajó como visitador de idolatrías a algunos pueblos en la provincia de Huaylas en los años 1620, documentó que aún cien años después de la conquista del imperio incaico por los españoles, los niños sacrificados en la Capacocha y sus tumbas seguían siendo recordados y venerados por sus ayllus (linajes). En las listas de las idolatrías de Recuay, Hernández Príncipe (1986 [1622]: 486, 489, 491, 493, 499) registró incluso las cifras exactas de los sacrificados así como mencionó las circunstancias peculiares y los motivos por los cuales habían sido dispuestos para la Capacocha. John Rowe escribe a propósito de esto que a través del recuerdo de los sacrificados y del conocimiento de sus tumbas:

«los sacrificios de la Capacocha proveían otro tipo de red que mantenía unido al gran reino de los incas» (Row, 1982: 110) (la traducción es mía).

Es obvio entonces que la influencia sobre los cultos locales por parte de la autoridad incaica fue algo persistente. 
Una Capacocha cumplía también otra función: servía de hito entre grupos colindantes formando una «frontera sacralizada por tratarse de un oráculo» (Gentile, 1996: 52). Las delegaciones que salían del Cuzco llevaban la ofrenda (no necesariamente consistiendo en un niño) de término a término, transportada cada vez por los habitantes de la región atravesada quienes la tenían que entregar a los vecinos una vez llegados a sus límites territoriales, reconociendo de este modo la frontera entre ellos (Rostworowski, 1988: 6567)4. Este mecanismo del reconocimiento de las fronteras entre grupos vecinos integrado en un contexto ritual representaba indirectamente otro medio del Estado incaico para ejercer control sobre los diferentes grupos étnicos del imperio.

El reclutamiento de los niños para los sacrificios se llevó a cabo de diferentes maneras: Molina de Cuzco (1988 [1575]: 128), por ejemplo, nos informa que con ocasión de conquistar territorios nuevos los incas escogieron a unos de los niños quienes más destacaban por su belleza, con el propósito de sacrificarlos al Sol en la capital de Cuzco y agradecer de este modo la victoria recientemente conseguida. De los datos que nos proporciona la visita de Diez de San Miguel (1964 [1567]: 39, 85, 92, 106), por otra parte, se deduce que los grupos sometidos también se veían obligados a poner a disposición regularmente a niños para los sacrificios incaicos, a saber en la base de los tributos. Según Rowe (1946: 306) a las niñas se las solía escoger frecuentemente entre las filas de las acllas (muchachas seleccionadas que vivían y trabajaban en conventos pertenecientes al estado). Aparte de eso existía significativamente en el incario otra posibilidad de reclutar a niños para los sacrificios. Y es justamente ésta la que nos muestra claramente la dimensión política del ritual: en los apuntes de Hernández Príncipe (1986 [1622]: 465, 473) se encuentra un caso concreto del cual se desprende que un curaca que se podía permitir poner a disposición una hija o un hijo tuvo la posibilidad de aumentar su autoridad dentro de las estructuras incaicas del poder. A través de esta ofrenda suprema y más valiosa el curaca se podía ganar el favor del Inca y —como compensación- esperar ascender políticamente. Hernández Príncipe nos informa también que incluso sucedió que los curacas no sólo lograron aumentar su autoridad ofreciendo un hijo suyo, sino que a veces el Inca no les otorgó el cargo hasta que no ofrecieran una Capacocha:

«Es cierto se han de hallar entre los caciques y gobernadores que por ellas [Capacochas] recibieron el cacicazgo» (Hernández Príncipe, 1986 [1622]: 474).

En resumen, se puede constatar que el modo de acción en la dimensión política de la Capacocha no se desarrolló exclusivamente a favor del Inca que intentaba vincular a las autoridades locales con su propio dominio, sino que en esta negociación política también hubo espacio considerable para los intereses de los curacas: en el contexto de la Capacocha ellos tenían la ocasión de distinguirse y de adquirir oportunidades de ascenso en las estructuras del poder bajo el dominio incaico.

\section{Referencias citadas}

BOHOLM, Å., 1996 - Introduction. In: Political Ritual (Asa Boholm, ed.): 1-13; Gothenburg: Institute for Advanced Studies in Social Anthropology.

4 Tal como nos ha llegado la información desde el tiempo de Huayna Capac por el documento del AGl Justicia 413 (véase Rostworowski, 1988) había grupos que —con ocasión de estas procesiones- aprovecharon la oportunidad de luchar por sus intereses y de declarar sus derechos a tierra ajena traspasando los linderos señalados y así tratando de negociar las fronteras hasta el momento existentes. 
BRAVO GUERREIRA, C., 1985 - La unificación andina de los Incas. In: Cultura y Religión de la América Prehispánica (Manuel Ballesteros Gaibrois, ed.): 259-295; Madrid: Biblioteca de Autores Cristianos.

CIEZA DE LEÓN, P., 1985 [155?] - El señorío de los Incas (Manuel Ballesteros Gaibrois, ed.), 211 p.; Madrid: historia 16.

CHÁVEZ CHÁVEZ, J. A., 2001 - Investigaciones arqueológicas de alta montaña en el sur del Perú. Chungará, 33 (2): 283-288; Arica. [online, citado 7 mayo 2006, disponible en la World Wide Web: <http://www.scielo.cl/scielo.php?script=sci arttext\&pid $=$ S0717-73562001000200014\&lng $=e s \& n r m=i s o>. \quad$ ISSN $0717-$ 7356].

DIEZ DE SAN MIGUEL, G., 1964 [1567] - Visita hecha a la provincia de Chucuito [...] en el año 1567 (Waldemar Espinoza Soriano, ed.), 445 p.; Lima: Ediciones de la Casa de la Cultura del Perú.

DUVIOLS, P., 1976 - La Capacocha. Allpanchis, 9: 11-58.

GARCILASO DE LA VEGA, el Inca, 1991 [1609] - Comentarios reales de los Incas, t. I (Carlos Araníbar, ed.), 411 p.; Lima Fondo de Cultura Económica.

GAREIS, I., 1987 - Religiöse Spezialisten des zentralen Andengebietes zur Zeit der Inka und während der spanischen Kolonialherrschaft, 517 p.; Hohenschäftlarn: Renner.

GAREIS, I., 2003 - Religion im Dienst der Macht. Politische Rituale in Spanien und seinen amerikanischen Besitzungen 16.-17.Jh., 23 p. (manuscrito inédito).

GAREIS, I., 2005 - Politische Rituale. Ein ethnologischer Vergleich an Fallbeispielen aus Lateinamerika, Afrika und Asien (manuscrito inédito).

GENTILE, M. E., 1996 - Dimensión sociopolítica y religiosa de la Capacocha del cerro Aconcagua. Bulletin de l'Institut Français d'Études Andines, 25 (1): 43-90.

HAGEN, A. von \& MORRIS, C., 1998 - The Cities of the Ancient Andes, 240 p.; London: Thames and Hudson.

HERNÁNDEZ PRÍNCIPE, R. 1986 [1622] - Idolatrías en Recuay, Provincia de Huailas. In: Cultura Andina y Represión. Procesos y visitas de idolatrías y hechicerías, Cajatambo, siglo XVII (Pierre Duviols, ed.): 483-507; Cusco: Centro de Estudios Rurales Andinos «Bartolomé de las Casas».

SALOMON, F. \& URIOSTE, G. L. (eds.), 1991 [21608?] - The Huarochirí manuscript. A Testament of Ancient and Colonial Andean Religion, 273 p.; Austin: University of Texas Press.

MOLINA DE CUZCO, C., 1988 [1575] - Relación de las fábulas y ritos de los Incas (Henrique Urbano \& Pierre Duviols, eds.), 199 p.; Madrid: historia 16.

MURÚA, M. de, 1986 [1611] - Historia general del Perú (Manuel Ballesteros Gaibrois, ed.), 583 p.; Madrid: historia 16.

REINHARD, J., 1992 - An Archaeological Investigation of Inca Ceremonial Platforms on the Volcano Copiapo, Central Chile. In: Ancient America: Contributions to New World Archaeology (Nicholas J. Saunders, ed.): 145-172; Oxford: Oxbow Books.

REINHARD, J., 2002 - A High Altitude Archaeological Survey in Northern Chile. Revista de Antropología Chilena, 34 (1): 85-99.

ROSTWOROWSKI DE DIEZ CANSECO, M., 1970 - Etnohistoria de un valle costeño durante el Tawantinsuyu. Revista del Museo Nacional, 35: 7-61.

ROSTWOROWSKI DE DIEZ CANSECO, M., 1988 - Conflicts over coca fields in XVIthcentury Perú, 314 p.; Michigan: Ann Arbor.

ROWE, J., 1946 - Inca culture at the time of Spanish conquest. In: Handbook of South American Indians, 2: 183-330. 
ROWE, J., 1982 - Inca Policies and Institutions Relating to the Cultural Unification of the Empire. In: The Inca and Aztec States 1400-1800. Anthropology and History (George Collier, Renato Rosaldo \& John Wirth, eds.): 93-118; New York: Academic Press.

TURNER, V. W., 1969 - The Ritual Process. Structure and Anti-Structure; London: Routledge \& Keagan Paul.

ZUIDEMA, T. R., 1973 - Kinship and ancestor cult in three Peruvian communities. Bulletin de I'Institut Français d'Études Andines, 2 (1): 16-33.

ZUIDEMA, T. R., 1982 - Bureaucracy and Systematic Knowledge in Andean Civilization. In: The Inca and Aztec States 1400-1800. Anthropology and History (George Collier, Renato Rosaldo \& John Wirth, eds.): 419-458. 